\title{
AIRFOIL SHAPED STRUTS FOR VERTICAL AXIS WIND TURBINE
}

\author{
Samyak Jain \\ Akhilesh Das Gupta Institute of Technology and \\ Management, Shastri Park, New Delhi, India
}

Varun Yadav

Akhilesh Das Gupta Institute of Technology and Management, Shastri Park, New Delhi, India

\author{
Gautam Singh \\ Akhilesh Das Gupta Institute of Technology and \\ Management, Shastri Park, New Delhi, India
}

Rahul Bisht

Akhilesh Das Gupta Institute of Technology and Management, Shastri Park, New Delhi, India

\begin{abstract}
Currently, many countries are racing towards switching to clean energy resource (1). Among the options available Solar and Wind are two viable options that are economically feasible. Each day a new development is helping in bringing down the cost of energy extracted from these sources.

With currently available technologies, solar energy is almost as expensive as the energy generated from burning coal, whereas wind energy is still slightly expensive (2). However, wind energy could be made cheaper by the use of a vertical axis wind turbine (3).

However, structure is a major factor that is holding back the development of VAWTs with better efficiency (4). The efficiency of a VAWT depends upon its aspect ratio. Aspect Ratio is the ratio of the height of the blade to the diameter of the turbine. The lower the aspect ratio, the higher the efficiency (5). However, decreasing the AR would mean either increasing the diameter of the turbine or the height of the blade. In either case, the bending moment would increase on the struts, that connect the blades to the shaft.
\end{abstract}

In this paper we propose, struts with airfoil cross-section. This is because, the lift generated by airfoil struts acts as additional support for the blade, thus increasing our ability to work at lower aspect ratios.

Keywords- Airfoil, Vertical Axis Wind Turbine, Renewable Energy, Wind Energy

\section{INTRODUCTION}

\subsection{Vertical Axis Wind Turbine (VAWT)}

Vertical axis wind turbines are turbines in which the blades rotate about a vertical shaft. They can capture the wind energy from any direction and are suitable under highly turbulent wind conditions. VAWTs can be classified into two broad categories, based on their principle.

\subsubsection{Savonius}

Savonius turbines are low-speed, high-torque turbines. They rely on drag force to generate torque (6).

\subsubsection{Darrieus}

Darrieus turbines consist of blades with airfoil cross-section. They capture wind energy in the form of lift generated by the flow of wind around the airfoil blades (7).

\subsection{Advantages of VAWT over HAWT}

- When we compare a vertical axis wind turbine with a horizontal axis wind turbine, the answer is clear: Vertical axis wind turbines cannot compete with horizontal axis wind turbines, particularly regarding power output and efficiency. But, there are several other factors where VAWTs perform better than HAWTs. Based on this fact, vertical axis wind turbines are the basis of our project.

- Horizontal axis wind turbines require a highly specialized study of the wind patterns and topographical features of the turbine installation site. Whereas, vertical axis wind turbines are more geographically flexible. VAWTs are independent of wind flow direction. Also, they are capable of generating power at low wind speed. This makes them great alternatives for conditions unsuitable for conventional and HAWT models. - Since VAWTs are independent of wind direction, they do not require any wind detection or orientation mechanism. This reduces the number of moving components, hence reducing the complexity of the system along with maintenance costs.

- The drive train of the vertical axis system can be placed near the surface. This provides two-fold benefits. Firstly, the maintenance process of the drivetrain becomes a lot easier and faster. Secondly, since the major bulk of the structure is near the ground, the centre of gravity is quite low. This tremendously improves the structural stability, hence making the support structure a lot cheaper than HAWTs. 


\section{International Journal of Engineering Applied Sciences and Technology, 2021 \\ Vol. 5, Issue 9, ISSN No. 2455-2143, Pages 162-165 \\ Published Online January 2021 in IJEAST (http://www.ijeast.com)}

- In wind farms, the turbines are required to be placed at a minimum optimum distance to avoid losses due to the turbulence effect and to allow the wind to recover its speed after rotating a turbine. This distance is less for VAWTs as compared to HAWTs. This helps in increasing the power density of wind farms by packing more wind turbines in a limited area. (8)

\section{LITERATURE}

Despite the advantages mentioned above, VAWTs have a major drawback, which is pulling them from operating at lower Aspect Ratio and hence give higher efficiency. Aspect Ratio is the ratio of the height of the blade to the diameter of the turbine. The lower the aspect ratio, the higher the efficiency (5). However, decreasing the AR would mean either increasing the diameter of the turbine or the height of the blade. In either case, the bending moment would increase on the struts that connect the blades to the shaft and hence decrease the capabilities of the structure.

This problem can be solved by replacing the traditional struts with airfoil cross-section struts. The lift generated by these struts while rotation would provide additional support to the blades, and would hence enable us to design turbines at the lower aspect ratios.

\subsection{Selection of Airfoils}

For this research, we chose symmetric airfoils, due to their simplicity and stable output. We analyzed the NACA series airfoil; 0012, 0013, 0014, 0015, 0016, 0017, 0018 using the BEM method on Qblade software.

\subsubsection{BEM method.}

BEM stands for Blade Element Momentum. It is a theory that combines both blade element theory and momentum theory. It is used to calculate the local forces on a propeller or windturbine blade (9).

Qblade is an open-source simulation software, based on BEM theory (10).

\subsubsection{Analysis Result}

The analysis showed that NACA0012 gave the maximum values lift coefficient over the span of 0-15 degrees of angle of attack.

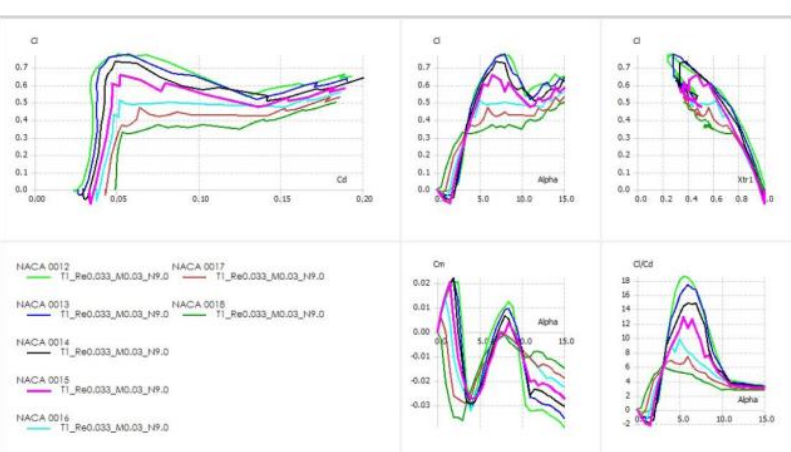

Figure 1: BEM analysis results

The angle of attack was chosen at 5.50 , as at that angle, the Lift to Drag ratio was maximum.

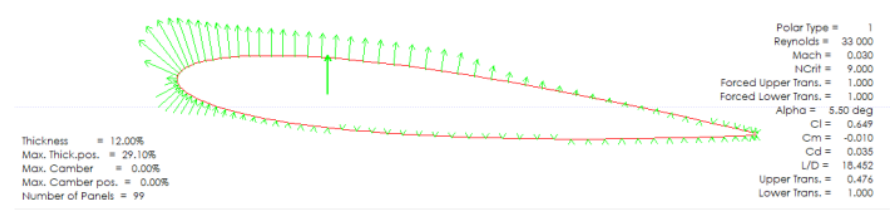

Figure 2: Angle of attack

\subsection{Structural Analysis}

Structural analysis was performed on ANSYS software on two geometries. One with hollow, skeleton-based airfoil struts with a chord length of $25 \mathrm{~cm}$ and the other with hexagon struts with an edge length of $2.5 \mathrm{~cm}$, available in the design library of the software. The following parameters were considered for the analysis.

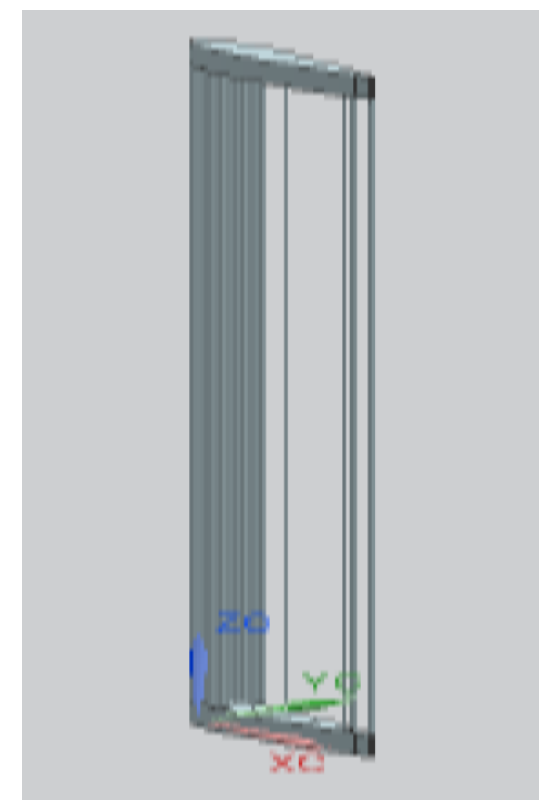

Figure 3: Airfoil Skeleton for struts

\begin{tabular}{|l|l|l|}
\hline S no. & Parameters & Value \\
\hline 1 & Material & Structural Steel \\
\hline
\end{tabular}




\begin{tabular}{|l|l|l|}
\hline 2 & Weight of Blade & $1666 \mathrm{~N}(170 \mathrm{~kg})$ \\
\hline 3 & Lift Generated & $40 \mathrm{~N}$ \\
\hline 4 & Rotational Velocity & $7.2 \mathrm{rad} / \mathrm{sec}$ \\
\hline
\end{tabular}

Table 1: Parameters of Analysis

\subsubsection{Results Obtained}

The results obtained predicted a much higher FOS for the shaft with airfoil struts.

While airfoil struts achieved the FOS of 1.08, hexagonal struts achieved the FOS of 0.61 .

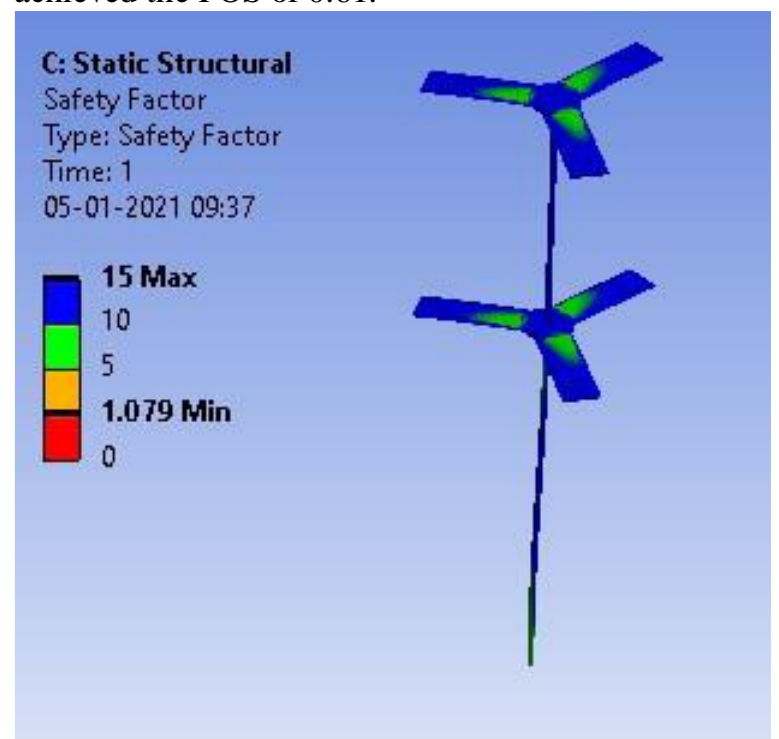

Figure 4: FOS of airfoil shaped struts

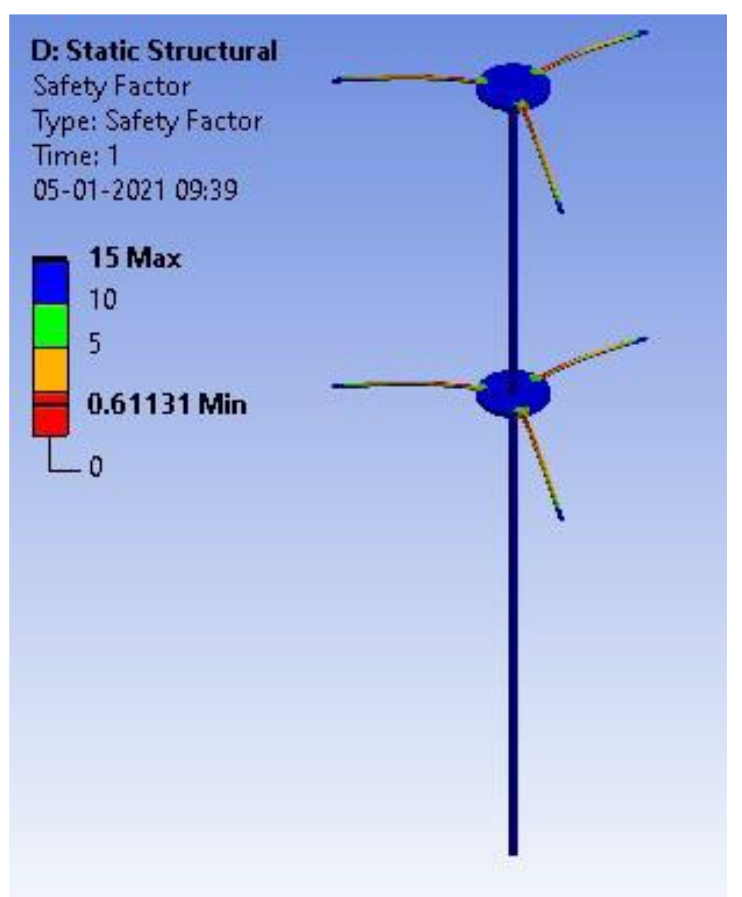

Figure 3: FOS of hexagon shaped struts

\section{CONCLUSION}

From the results stated above, we can safely conclude that airfoil struts can improve the structural strength by as much as $80 \%$, thus allowing us to design wind turbines with higher efficiency.

\section{REFERENCE}

[1] Brusca, S., Lanzafame, R., \& Messina, M. (2014). Design of a vertical-axis wind turbine: how the aspect ratio affects the turbine's performance. International Journal of Energy and Environmental Engineering, 5(4), 333-340. https://doi.org/10.1007/s40095-014-0129-x

[2] Digital Commons, C., \& Winslow, A. R. (2017). Urban Wind Generation: Comparing Horizontal and Vertical Axis Wind Turbines at Clark University in Worcester, Massachusetts.127. https://commons.clarku.edu/idce masters_papers/127

[3] E.A.D. Kumara K.G.R.M. Jayathilake, N. K. H. (2017). Review Paper- Overview of the Vertical Axis Wind Turbines. International Journal of Scientific Research and Innovative Technology, 4(September), 56-67.

[4] El Khchine, Y., \& Sriti, M. (2018). Improved blade element momentum theory (BEM) for predicting the aerodynamic performances of horizontal axis wind turbine blade (HAWT). Technische Mechanik, 38(2), 191-202. https://doi.org/10.24352/UB.OVGU-2018-028

[5] Ghasemian, S., Faridzad, A., Abbaszadeh, P., Taklif, A., Ghasemi, A., \& Hafezi, R. (2020). An overview of global energy scenarios by 2040: identifying the driving forces using cross-impact analysis method. International Journal of Environmental Science and Technology, 0123456789. https://doi.org/10.1007/s13762-020-02738-5

[6] Johari, M. K., Jalil, M. A. A., \& Shariff, M. F. M. (2018). Comparison of horizontal axis wind turbine (HAWT) and vertical axis wind turbine (VAWT). International Journal of Engineering and Technology(UAE), 7(4), 74-80. https://doi.org/10.14419/ijet.v7i4.13.21333

[7] Liu, W., \& Lund, H. (2009). Comparative Study of the Potential of Renewable Energy Sources and Solutions between Denmark and China. Joint Actions on Climate Change, May 2014, 1-11. http://scholar.google.com/scholar?hl=en\&btnG=Search\& q=intitle:Opportunities+in+Renewable+Energy+Business +in+South-

East+Asia: + The +case+of+Solar+Photovoltaics+and+Sola r+Drying\#2\%5Cnhttp://ijens.org/106106-0505 IJBASIJENS.pdf

[8] Marten, D., Peukert, J., Pechlivanoglou, G., Nayeri, C., \& Paschereit, C. (2013). QBLADE: An Open Source Tool for Design and Simulation of Horizontal and Vertical Axis Wind Turbines. International Journal of Emerging Technology and Advanced Engineering, 3, 264-269. 
[9] Tjiu, W., Marnoto, T., Mat, S., Ruslan, M. H., \& Sopian, K. (2015). Darrieus vertical axis wind turbine for power generation I: Assessment of Darrieus VAWT configurations. Renewable Energy, 75(February 2019), 50-67. https://doi.org/10.1016/j.renene.2014.09.038

[10] Zemamou, M., Aggour, M., \& Toumi, A. (2017). Review of savonius wind turbine design and performance. Energy Procedia, 141(August 2018), 383-388. https://doi.org/10.1016/j.egypro.2017.11.047 